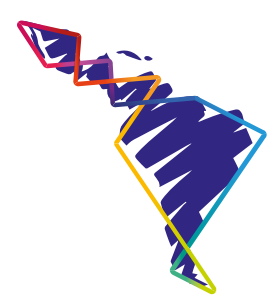

\title{
El genocidio reorganizador en Colombia: el asesinato de líderes sociales y defensores de derechos humanos como genocidio contra un grupo nacional
}
The reorganizing genocide in Colombia: the murder of social leaders and human rights defenders as a genocide against a national group
0 genocídio em reorganização na colômbia: o assassinato de líderes sociais e defensores dos direitos humanos como genocídio contra um grupo nacional

Juan Felipe Castañeda Durán ${ }^{1}$

\begin{abstract}
Resumen
Los asesinatos de líderes sociales y defensores de derechos humanos no son acontecimientos aislados, sino que responden a un plan sistemático de exterminio contra los liderazgos de las poblaciones opuestas a la imposición de un modelo económico latifundista, extractivista y agroindustrial. El presente artículo, a través de la identificación del grupo nacional que representan los defensores de derechos humanos y líderes sociales, así como de los actores que están exterminándolos, hace un estudio del concepto del genocidio desde el softlaw, para argumentar
\end{abstract}

1 Abogado especialista en justicia transicional, víctimas y construcción de paz de la Universidad Nacional de Colombia. Integrante del Colectivo de Abogados José Alvear Restrepo, entre los años 2018 y 2020; actualmente se desempeña como abogado parte de la Fundación Nydia Erika Bautista, Colombia. Correo electrónico: jfcastanedad@unal.edu.co. ORCID: https://orcid.org/0000-0003-2777-2900 
por qué el asesinato de esta población constituye un genocidio cimentado en la doctrina de la seguridad nacional, que ha adoptado distintas formas a lo largo de su aplicación en Colombia.

Palabras clave: genocidio contra grupo nacional, reorganización nacional, seguridad democrática, líderes sociales y defensores de derechos humanos.

\begin{abstract}
The murders of social leaders and human rights defenders are not isolated events, but rather respond to a systematic plan of extermination against the leaders of the populations that oppose the imposition of a latifundist, extractivist and agro-industrial economic model. The present article, through the identification of the national group represented by human rights defenders and social leaders and of the actors that are exterminating them, unveils a study of the concept of genocide from the perspective of softlaw to argue why the murder of this population constitutes a genocide based on the doctrine of national security, which has taken different forms throughout its application in Colombia.
\end{abstract}

Keywords: Genocide against national group; National reorganization; Democratic security; Social leaders and human rights defenders.

\title{
Resumo
}

Os assassinatos de lideranças sociais e defensores dos direitos humanos não são eventos isolados, mas respondem a um plano sistemático de extermínio contra os líderes das populações que se opõem à imposição de um modelo econômico latifundiário, extrativista e agroindustrial. Este artigo, por meio da identificação do grupo nacional representado por defensores dos direitos humanos e lideranças sociais e dos atores que os exterminam, faz um estudo do conceito de genocídio a partir da soft law para argumentar porque o assassinato dessa população se constitui um genocídio baseado na doutrina da segurança nacional, que assumiu diferentes formas ao longo de sua aplicação na Colômbia.

Palavras-chave: Genocídio contra grupo nacional; Reorganização nacional; Segurança democrática; Líderes sociais e defensores dos direitos humanos.

“... El problema está en los ojos cuando ya no dicen nada, cuando echamos el cerrojo y caminamos en manada rumbo a fosas de despojos, donde se halla desmembrada, toda identidad y arrojo de una humanidad domada..." Paradoxus Luporum - El cementerio está lleno de cobardes.

En Colombia están asesinando sistemáticamente a líderes sociales y defensores de derechos humanos (LSyDDH), en especial, aquellos que defienden su territorio de injerencias de grupos económicos y grupos alzados en armas que tienen intereses económicos en sus tierras (Castañeda, 2019). Estos crímenes sistemáticos no son fortuitos y responden a un proceso de reorganización social que han adelantado 
"los perpetradores" (pp. 5-6), con la finalidad de generar una alteración de los modos de funcionamiento de la interacción social en estas regiones para, de una parte, imponer un modelo de desarrollo económico y, de otra, alterar, a través de la muerte y el horror, los modos imperantes de relacionamiento y los vínculos sociales de los habitantes (Feierstein, 2008).

Teniendo en cuenta lo esbozado, el presente trabajo pretende justificar que el asesinato de LSyDDH en Colombia es parte de un "genocidio reorganizador", el cual comenzó con el genocidio de la Unión Patriótica (gestado con el propósito de eliminar la amplia resistencia al proyecto neoliberal y su rechazo por el grueso de la sociedad); se consolidó con la atomización de la sociedad y la ruptura del vínculo social generadas por los "falsos positivos", que fueron parte de la política de la seguridad democrática; y finalmente, está terminando de imponerse mediante el asesinato de los LSyDDH de los territorios donde aún no se ha fijado el proyecto reorganizador por la resistencia de los habitantes de esos lugares al modelo económico, político y social que les quieren imponer. Así, se parte de la hipótesis de que, a través de este "genocidio reorganizador", los perpetradores pretendieron y pretenden inducir unas profundas transformaciones a un Estado nación preexistente (Colombia) para alterar sus modos de funcionamiento social. Con tal afán, se valen de prácticas violatorias de derechos humanos, $\mathrm{y}$, a través del terror, destruyen los vínculos sociales entre los habitantes, así como eliminan cualquier atisbo de resistencia o de contradicción con el modelo económico (extractivista, latifundista) que quieren imponer (Feierstein, 2008).

Para llevar a cabo lo dicho, se dividirá el trabajo en los siguientes acápites: I. Marco teórico, conceptual e histórico; II. El asesinato de líderes sociales y defensores de derechos humanos en los territorios como "genocidio reorganizador" y la adecuación típica de estos asesinatos como genocidio contra un grupo nacional; III. Conclusiones y IV. Reflexión final.

\section{Marco teórico, conceptual e histórico}

En este acápite, se desarrollarán las categorías que se utilizarán a lo largo del trabajo.

\section{Grupo por proteger: líderes sociales y defensores de derechos humanos}

\section{Identificación del grupo}

En un trabajo previo, se definió la categoría LSyDDH (Castañeda, 2019). En esa ocasión, se dijo que eran defensores de derechos humanos todas aquellas personas que 
... a través de los mecanismos legales nacionales e internacionales, procuran por la defensa de los derechos de quienes se encuentran protegidos por la órbita del Estado, porque o bien este no les brinda las suficientes herramientas para salvaguardar sus derechos humanos, o bien les pone trabas para impedir el disfrute de los mismos (p. 3).

En este sentido, se indicó también que los líderes sociales eran todas aquellas personas que

... ganándose la aceptación de su comunidad y pensando en el beneficio de la misma, lideran a diversos grupos sociales para procurar el mejoramiento de su calidad de vida, así como por el respeto de su dignidad; la categoría de líderes sociales agrupa a diversos tipos de líderes, como por ejemplo líderes agrarios, líderes estudiantiles, líderes campesinos, líderes indígenas, entre otros... (2019, p. 3).

El grupo de los LSyDDH, si bien es diverso, con personas que tienen reivindicaciones y luchas heterogéneas (que van desde la defensa de la tierra hasta las luchas por el derecho a la educación), es homogéneo en términos políticos, en cuanto son sujetos en continua resistencia contra la imposición hegemónica de distintos actores económicos y armados (perpetradores), para defender los derechos e intereses de sus comunidades. En efecto, aunque no se trata de un grupo uniforme en lo étnico ni racial, sí tiene consonancia en cuanto a sus reivindicaciones, objetivos e ideales, pues a estas personas las une su esfuerzo por la defensa de sus comunidades y territorios.

Ello no es un tema menor, porque, al ser los LSyDDH un eslabón importante en la cohesión social, su muerte — desde la perspectiva de los perpetradores - sería fundamental para la desarticulación de los últimos vestigios de resistencia que pudieran encontrar en las comunidades en las cuales quieren imponer un modelo de desarrollo económico y un nuevo orden tanto social como político.

Así, los LSyDDH son una pieza fundamental para el mantenimiento de las relaciones en el grupo social, al ser las personas que visibilizan, representan a sus comunidades y defienden los intereses de sus cohabitantes frente a la imposición de modelos de conducta, económicos, así como de órdenes sociales y políticos por parte de los perpetradores (Langheinrich, 2017).

\section{Caracterización del grupo}

El grupo de LSyDDH comparte creencias e ideas sobre la manera en la cual deberían darse las relaciones políticas, económicas y sociales al interior de cada una de sus comunidades, en las cuales prima la defensa de los intereses de estas ante los 
ataques y las injerencias de unos actores armados y económicos, quienes tienen intenciones monetarias sobre sus tierras y territorios (Somos Defensores, 2018). En este sentido, la agrupación mencionada posee una identidad política común.

Además de lo anterior, también tienen una identidad común en las agresiones que sufren en razón de su defensa del territorio y su oposición a proyectos extractivistas, agroindustriales así como a un modelo de desarrollo basado en la depredación del ambiente (Comisión IDH, 2011).

Siguiendo lo anterior, puede decirse, de igual modo, que los LSyDDH tienen una identidad común en la percepción de sus comunidades y los perpetradores que están detrás de sus asesinatos: para sus localidades son un eje, un foco, las personas a las que acuden los habitantes de cada región para informarles los problemas y solicitar ayuda; son el engranaje comunitario y quienes mantienen la cohesión social en medio de las adversidades.

Para los actores que los asesinan, por otro lado, los LSyDDH son "la piedra en el zapato" (Somos Defensores, 2018), pues organizan las comunidades para que se opongan a sus proyectos económicos en los territorios; sin embargo, también los reconocen como pieza fundamental de la cohesión social, por lo cual son aquellos que declaran "objetivos militares" (Lederach, 2003).

\section{Perpetradores y sus objetivos}

Los perpetradores son, fundamentalmente, agentes estatales y grupos paraestatales financiados por actores económicos, que tienen el objetivo de ingresar a los territorios para adelantar proyectos productivos de índole extractiva, por una parte, o acaparar tierras (latifundismo), con el fin de adelantar actividades relacionadas con la ganadería, los monocultivos o proyectos minero-energéticos (Torres, 2018) -que incluyen, por supuesto, también actividades vinculadas al narcotráfico-, de otra. Dado que estos perpetradores encuentran en su camino la resistencia de los LSyDDH, por medio de sus brazos armados, como ya se aludió, los declaran "objetivo militar", obligándolos a retirarse del sitio donde ejercen vocería o defensa del territorio y sus comunidades, en contra de los intereses de los primeros (Guevara, 2019).

El objetivo de los perpetradores, en este caso, es la imposición de un modelo económico, que se basa en el extractivismo y en el mantenimiento de los latifundios a través del terror. Para ello, se fundan también en la implantación de un orden social, caracterizado por utilizar métodos que generan terror o zozobra constante en la población, como amenazas indirectas o indirectas, muestras de uso de la 
fuerza e incluso el asesinato de algunos de sus integrantes o masacres contra la población. Tal modelo de orden social emplea como mecanismo la "delación" (Feierstein, 2008) para erosionar las relaciones sociales cimentados en la confianza, generando un ambiente de desconfianza que elimina el ligamen entre los habitantes y los atomiza (Feierstein, 2008). Lo anterior, con dos objetivos fundamentales: i) que los habitantes dejen de relacionarse entre sí y solo confíen en el Estado o los grupos paraestatales, a los que les dan información sobre sus vecinos, para evitar que ellos los delaten primero; ii) impedir que se generen procesos de empatía que permita a la comunidad organizarse y oponerse a los proyectos económicos que los perpetradores quieren imponer en sus comunidades y territorios.

\section{Genocidio}

\section{Génesis del concepto de genocidio}

El genocidio como concepto surge gracias a la aproximación que hizo Raphael Lemkin (2008), a propósito del dominio del Eje sobre Europa. Lemkin, inicialmente, consideró que el genocidio se refería a la negación de la existencia de grupos humanos, en donde las acciones realizadas hacían parte de un plan coordinado que buscaba la aniquilación de esas agrupaciones humanas a través de la aniquilación de sus integrantes, por lo cual el sujeto aniquilado no era eliminado por su condición subjetiva sino por su afiliación a dichos grupos. Para Lemkin, las técnicas genocidas se realizaban en ocho campos: económico, biológico, social, cultural, físico, religioso, moral y político (Lemkin, 2008).

Sin embargo, la definición fue acortándose, en parte por la propia iniciativa de Lemkin, quien, paradójicamente, apoyó la exclusión de los grupos políticos del concepto "genocidio", en el documento definitivo de la Convención para la prevención y sanción del delito de genocidio (1948) (Feierstein, 2008).

Si bien los grupos "políticos" fueron tenidos en cuenta en el primer borrador de la Convención, más tarde se descartaron en el proyecto definitivo, bajo argumentos más bien dudosos. En ese momento, se afirmó que eran un grupo "difuso" carente de la "permanencia" que sí tenían otros; no obstante, pese a que parcialmente es cierto lo afirmado, ello no explica por qué otros grupos como los "religiosos" sí son protegidos en la Convención, pues también son "difusos" y no necesariamente "permanentes". Además, ambos grupos, tanto el político como religioso, basan su cohesión en un sistema compartido de creencias.

Descartados los argumentos por los cuales se excluyó el grupo político como protegido, resta decir que las razones no obedecen a la lógica o inconveniencia teórica, 
sino que, más bien, responden a asuntos políticos (Ambos, 2004). Algunos Estados se opusieron a la inclusión de agrupaciones políticas protegidas para blindar las prácticas sociales genocidas, (p. 10) pasadas, presentes y futuras, que pensaban realizar (Churchill, 1997); esto es, desaprobaron incluir como grupo protegido por la Convención aquel que tenían la intención de aniquilar en las décadas posteriores.

\section{El concepto de "genocidio" en el Estatuto de Roma}

En el Estatuto de Roma (1998), el genocidio está reconocido en el artículo 6. Allí se indica que será genocidio "cualquiera de los actos mencionados a continuación, perpetrados con la intención de destruir total o parcialmente a un grupo nacional, étnico, racial o religioso como tal" (Estatuto de Roma, 1998, art. 6).

Como puede evidenciarse, el Estatuto de Roma no contempla al grupo político como protegido contra el genocidio, de manera directa, sin embargo, hubo algunas aproximaciones de tribunales ad hoc en este sentido. Así, en el caso seguido contra Rutaganda (TPIR, 1999), el tribunal consideró que es muy difusa la distinción entre los distintos grupos protegidos y, por ende, la pertenencia a uno de ellos es un concepto subjetivo más que objetivo, en esencia. Se consideró que el perpetrador del genocidio percibe a la víctima como perteneciente a un grupo destinado a su destrucción; además de ello, cada concepción relacionada con el grupo protegido debe analizarse en un contexto político, social y cultual determinado (Ambos, 2004).

Sobre este último punto, el Tribunal Penal Internacional para la ex Yugoslavia estimó que para que unas determinadas acciones se pudieran catalogar como genocidio tenían que causar un daño sustantivo o generar una destrucción significativa del grupo social. Con el fin de establecerlo, según ese Tribunal, debía atenderse al liderazgo, político, administrativo, religioso, etc., de una población y cómo la acción afectaba el destino del resto del grupo (Bjornlund, Markusen y Mennecke, 2005).

Hasta aquí, se puede colegir que en el Estatuto de Roma no hay una protección directa al grupo político y que tampoco la hubo en los casos adelantados por los "tribunales ad hoc", sin embargo, estos últimos relacionaron la destrucción "sustantiva", así como la construcción del grupo protegido, a partir de criterios que involucran lo político, en particular, cuando se refieren a la afectación al resto del grupo por la eliminación de sus líderes políticos. Es decir, desde la concepción actual del genocidio en el derecho penal internacional, el liderazgo político per se no es protegido por el Estatuto, solo en tanto esté enlazado con la posibilidad de supervivencia de uno de las agrupaciones protegidas. 
En este punto, hay que decir que el derecho penal internacional positivo (hard law) es insuficiente, pues se limita a una definición de genocidio que ha sido establecida convencionalmente, pero ello no significa que allí se agote la discusión sobre dicho término. En esta línea, parece coherente apoyarse en lo planteado por Daniel Feierstein, cuando indica que la discusión conceptual debe ser pensada más allá del derecho (2008). Lo anterior tiene una mayor pertinencia, si tenemos en cuenta que la categoría del genocidio es una construcción social dependiente, en gran parte, de la voluntad política de los Estados, pues como ya se indicó (p. 5), en buena medida, se excluyeron los grupos políticos justo por la falta de voluntad política de algunos Estados-potencias, en aras de "reorganizar" el escenario político global a través del asesinato del contrario.

\section{La justiciabilidad del genocidio político en el derecho internacional y la relación entre el genocidio político y el genocidio contra un grupo nacional}

El genocidio político no ha sido pasible de justiciabilidad de manera directa, sin embargo, sí se han hecho algunos esfuerzos para lograr justicia en estos casos. En lo subsiguiente, se utilizarán algunos criterios de soft law que darán cuenta de un interés de la comunidad internacional por la ampliación de la categoría de los grupos protegidos, para cubrir también los políticos. Luego de ello, se mencionará la relación entre grupo político y grupo nacional por parte de la jurisprudencia de Baltasar Garzón y Carlos Rozanzki, con miras a la protección de los grupos políticos y. Por último, se hará un comentario sobre la consideración, en el derecho interno colombiano, del genocidio político como genocidio.

Para pasar al punto número uno, se puede hablar de un primer antecedente visible de la consideración del genocidio político como "genocidio", en el informe presentado por Benjamín Whitaker a la Subcomisión de Prevención de la Discriminación y Protección de las Minorías de la Comisión de Derechos Humanos del Consejo Económico y Social de la ONU, en 1985. Este sostiene, entre otras premisas, que la exclusión de los grupos políticos genera una desprotección injustificada, en tanto que los criterios para excluirlos no justifican por qué son resguardados los grupos religiosos, pero no los políticos. El señor Whitaker, además, rescató lo mencionado por el representante francés, quien proféticamente indicó que, en el futuro, los genocidios serían políticos y por ello había que insistir en la protección de este grupo.

En los casos fallados por Baltasar Garzón y Carlos Rozanzki, se utilizó la noción de "grupo nacional" para suplir el defecto normativo ya esbozado de la no inclusión directa de los grupos políticos en los protegidos por el crimen del genocidio. 
En el histórico caso adelantado, contra Augusto Pinochet, por parte de Baltasar Garzón, este consideró, basándose en los instrumentos citados en este trabajo, como el Informe Whitaker y el primer borrador de la Resolución 96 de 1946, que se configuraba el delito de genocidio; si bien el concepto de grupo nacional no es idéntico al de grupo político, el primero sí contiene al segundo, pues dichos instrumentos internacionales consideran que, por una parte, que no es necesaria la eliminación de todo el grupo nacional para constituir el genocidio y, por otra, que esta categoría incluye "subgrupos" nacionales que están constituidos por grupos políticos. Así, el juez Garzón contempló que:

... el concepto de genocidio es un concepto vivo y que necesariamente debe de incluir aquellos supuestos que realmente le dan sentido a la luz de los acontecimientos que se han ido produciendo desde la entrada en vigor de la Convención. Uno de los supuestos que más claramente apoya esta interpretación, que no debe entenderse como extensiva, sino comprensiva del verdadero alcance que debe darse al término grupo nacional, es el ya citado de Autogenocidio de Kampuchea (...) [que] fue un verdadero genocidio de grupos nacionales por motivos políticos, aunque llegó a afectar no solo al mismo grupo Khmer de los aniquiladores, sino también a los propios Khmer rojos ideológicamente discrepantes del grupo dirigente (Juzgado Central de Instrucción, 1998, tercer razonamiento jurídico).

De ello saltan a la luz dos cosas: la primera, como es evidente, que la noción de genocidio es un concepto vivo, por lo que debería ir modificándose y acomodándose a la realidad social existente, tal como lo sentenciaba el representante francés: en el futuro - y el futuro es hoy - los genocidios se dan principalmente por motivos políticos; la segunda, que en efecto los grupos nacionales no están constituidos por sujetos homogéneos, sino que cada uno tiene dentro de sí múltiples subgrupos alineados según convicciones ideológicas, morales y políticas, por lo que la eliminación de un subgrupo nacional por parte del grupo nacional hegemónico es evidentemente un genocidio de una agrupación nacional.

En esta misma línea, se encuentra la sentencia promulgada por el Tribunal Oral en lo Federal No. 1 de la Plata (2006), en el juicio adelantado contra Miguel Etchecolatz, en la cual el juez Carlos Rozanzki, junto con los otros magistrados integrantes de la sala, reconoció que lo ocurrido durante la dictadura argentina, en especial los actos realizados por Etchecolatz, fueron un genocidio perpetrado contra el "grupo nacional argentino". Llegados a este punto, se cree que es acertada la conclusión de Daniel Feierstein: "de un modo u otro, el concepto de genocidio se va delineando en el derecho como lo que fuera inicialmente para la (...) (Resolución 96/1 de 1946): un modo de aniquilamiento de un grupo de población como tal" $(2008$, p. 57). 
Por último, hay que señalar que, en el ordenamiento interno colombiano sí está tipificado el genocidio político como genocidio, en el artículo 101 de la ley 599 del 2000 , por lo cual se refuerza la idea de que la categoría de genocidio es una categoría "viva" y depende, en buena medida, de la voluntad política de quienes hacen las normas. En Colombia, la razón de esa tipificación coincide con el tristemente célebre genocidio de la Unión Patriótica, que ocurrió entre 1985 y 1993. Según la Corporación Reiniciar y el Centro Nacional de Memoria Histórica sucedieron más de 4000 asesinatos o desapariciones forzadas (Sala de Reconocimiento de Verdad, 2019), cifra mucho mayor a la que en su momento se conocía cuando se presentó el caso ante la Comisión Interamericana de Derechos Humanos (CIDH, 1997). A raíz de esta masiva criminalidad, así como gracias a la movilización de las organizaciones defensoras de derechos humanos y las víctimas logró tipificarse el genocidio político en el ordenamiento interno colombiano.

\section{El genocidio reorganizador}

Antes de pasar a la categoría del genocidio reorganizador, se deben abordar unas cuestiones en lo referente a la categoría "genocidio". Para efectos de este trabajo, se considera acertado lo que plantea Feierstein en cuanto al uso de la expresión "práctica social genocida" en vez de genocidio y limitar la categoría "genocidio" al campo jurídico. Lo anterior aludiendo a que, si es concebido el genocidio como una práctica social, se evitan de entrada aquellas perspectivas tendientes a cosificar los procesos genocidas equiparándolos a fenómenos "naturales"; en efecto, el genocidio como práctica social implica un procedimiento llevado a cabo por seres humanos, el cual requiere aprendizaje, entrenamiento, perfeccionamiento, legitimación y búsqueda de consenso, por lo que no es una práctica espontánea.

Asimismo, el referirse a un concepto de "construcción" implica también que es un proceso pasible de "deconstrucción", por lo que los aportes académicos son fundamentales para la acción política y los procedimientos de resistencia. Por otro lado, la concepción del genocidio como práctica social "remite a una permanente incompletitud" (2008, p. 36), por lo cual se considera que las prácticas sociales genocidas en realidad no tienen una finalización, es decir, no acaban con una masacre, pues constituye un proceso inacabado inacabadas degenerativo de la concepción del otro.

De esta manera, las prácticas sociales genocidas son tanto aquellas que labran el camino al genocidio - que inicia con la construcción subjetiva de otro negativocomo su realización y su "justificación" o la realización simbólica de modelos de narración de dicha experiencia. En suma: el concebir el genocidio como un 
proceso que inicia antes y continúa después del aniquilamiento permite identificar las prácticas genocidas de manera temprana y saber cómo lidiar con sus efectos.

Entrando en la materia, el genocidio reorganizador es definido por Feierstein (2008, p. 100) como "... la aniquilación cuyo objetivo es la transformación de las relaciones sociales hegemónicas al interior del Estado nación preexistente". En este tipo, el genocidio no es el fin sino más bien el medio: "la desaparición de quienes corporizan determinadas relaciones sociales es condición necesaria pero no suficiente para la clausura de dichas relaciones. En realidad, el proceso se encuentra dirigido al conjunto social" (p. 104). Por tanto, las prácticas de terror empleadas por los agentes reorganizadores "no opera[n] tan solo sobre la víctima sino, fundamentalmente, sobre el conjunto social, buscando desterrar y clausurar determinadas relaciones sociales, a la vez que fundar otras" (p. 104).

El genocidio reorganizador “opera hacia el 'interior' de una sociedad ya constituida (...) y busca refundar las relaciones sociales, los vínculos, los códigos, la cotidianidad, las mediaciones políticas; en suma, el ejercicio concreto y abstracto del poder en dicha sociedad" (pp. 104-105).

Por otra parte, se debe señalar que este genocidio opera desde la noción del enemigo interno o del mal interior de la sociedad que debe ser exterminado; para esto, Feierstein utiliza la metáfora del tumor que requiere ser extirpado por el médico, a fin de que no se reproduzca más y cause daños más graves. En efecto, este pensamiento cumple un proceso de varias etapas que se mencionarán más adelante, pero, en particular, interesa el hecho de que el propósito último del genocidio es eliminar los focos de resistencia frente a determinadas políticas e intereses económicos. Es decir, tales focos de resistencia frente a los intereses del modelo económico agroexportador, rentístico (2008), entre otros, son el "tumor" que se necesita eliminar, con el afán de promover el desarrollo de un determinado modelo económico impuesto por los sujetos que detentan el poder económico y político.

En suma, el genocidio reorganizador se realiza al interior de una sociedad constituida y busca alterar, a través de la muerte y el horror, los modos hegemónicos de las relaciones sociales. Esto, con la finalidad de destruir los vínculos que mantienen unidas a diversas organizaciones políticas, obreras, barriales o estudiantiles, entre otras, opuestas al modelo económico extractivista y latifundista, el cual se quiere imponer, por parte de las élites económicas y políticas, sobre los intereses comunitarios.

Visto el concepto de genocidio reorganizador, debe recalcarse que este constituye un "proceso" con una serie de etapas o pasos mediante los cuales el "grupo reorganizador" o genocida logra la asimilación del nuevo orden social, político 
y económico que quiere imponer al conjunto social. Al respecto, se debe señalar que tal procedimiento inicia con la marcación negativa de un determinado grupo social, a partir de rótulos construidos alrededor de todos los temores presentes en la sociedad en ese momento histórico. Así, en el caso colombiano, se ha construido la imagen de los LSyDDH como "potenciales guerrilleros o colaboradores de la guerrilla" (Tribunal Superior Distrito Judicial de Medellín, Sala de Justicia y Paz, 2015), lo que genera su marcación negativa y hace más fácil su “deshumanización”, para convertirlos en ese "tumor" por extirpar; hecho que finaliza con el exterminio definitivo del grupo "marcado", no solo físico, sino también simbólico, histórico y social. Esta matanza no es solo una demostración de poder, además es un mensaje para todos los demás grupos que intenten oponerse a las políticas que está llevando a cabo el perpetrador (Feierstein, 2008).

Se debe señalar, tal como lo advierte Feierstein (2008), que las etapas no son sucesivas, sino que pueden presentarse de distintas maneras. De tal modo, puede primero llevarse a cabo la matanza y después argumentar que las víctimas fueron asesinadas porque "hacían parte de un comando guerrillero", con lo que se genera la estigmatización después de la eliminación física. De cualquier manera, son etapas que ocurren y se deben tomar como "alertas tempranas" para evitar que degeneren hasta genocidios.

Los genocidios, entonces, comienzan (i) con la construcción negativa de un sujeto o un grupo social; tras ello, este grupo social (ii) es hostigado en razón de la negatividad que se le está atribuyendo y es perseguido por ser "el mal" encarnado en la sociedad, que la corrompe y la perjudica; luego viene (iii) el aislamiento, que tiene la finalidad quebrar los lazos de este grupo social o estos sujetos que mantienen con el resto de grupos en la sociedad; después (iv) se generan políticas de debilitamiento sistemático, las cuales tienen la función de eliminar cualquier posibilidad de resistencia del grupo social a las acciones que se intenten en contra. Así, en el caso colombiano, es bien sabido en sucesos como la "masacre de Mapiripán”, cuando el Ejército Nacional se retiró de la zona y dejó a los habitantes desprotegidos en contra de la avanzada paramilitar.

Más tarde, ocurre (v) el aniquilamiento material y, por último, (vi) la realización "simbólica" de las prácticas sociales genocidas (Feierstein, 2008), que consiste en la negación de la identidad de las víctimas, asociándolas al grupo marcado negativamente y desmintiendo, con recurrencia, que hubiesen sido victimizadas. Aquí surge el común "algo estaría haciendo" o, en nuestro contexto, "no estaría recogiendo café", ideas que nacen como modos de legitimación del genocidio y constituyen la piedra angular de las prácticas sociales genocidas: la eliminación 
histórica y definitiva de la víctima (en tanto víctima), exterminio que también perpetúa el genocidio.

\section{Los genocidios políticos en Colombia como genocidios reorganizadores}

En este apartado, se hará un breve recuento histórico de los genocidios en Colombia, tomando para ello dos referentes históricos: el primero, el genocidio de la Unión Patriótica, como uno de los tantos simultáneos ocurridos con ocasión de la doctrina de la seguridad nacional, representada en el Estatuto de Seguridad de Julio César Turbay; el segundo, las ejecuciones extrajudiciales conocidas como "falsos positivos" que, si bien se recogen en una buena medida en la doctrina de la seguridad nacional, también tienen una fuerte influencia de la doctrina de la lucha antiterrorista.

$\mathrm{Al}$ respecto, se debe señalar, previamente, que tanto la doctrina de la seguridad nacional como la de la lucha antiterrorista son doctrinas militares y tácticas provenientes de Estados Unidos. La primera tuvo su máxima expresión con el Plan Cóndor que incidió en las dictaduras de Chile, Argentina, Uruguay y Brasil, en el cono sur; tanto en las ejecuciones extrajudiciales como en las desapariciones acaecidas en Colombia y México, y en el surgimiento de grupos paramilitares en Centroamérica y en Colombia. La segunda, por su parte, tuvo fuerte influencia en el discurso del entonces presidente de Colombia (2002-2010) Álvaro Uribe Vélez, quien negó la existencia de un conflicto armado interno y justificó el accionar de las fuerzas militares. Esto, en gran parte, se hizo en asocio con grupos paramilitares, bajo la excusa de que eran males necesarios para eliminar "la amenaza terrorista".

La doctrina de la seguridad nacional, basada en la noción del "enemigo interno" y en la lucha anticomunista, permitió equiparar a las personas con proyectos políticos alternativos y a los defensores de los derechos de sus comunidades con el "enemigo" al que había que destruir por "el bien" del país - representado por el modelo económico extractivista- (Castañeda, 2019). Fue así como en Colombia se homologó a los integrantes de la Unión Patriótica como "comunistas" o "guerrilleros" que iban a traer la "amenaza comunista" al país, dado que se trataba de un partido que surgió en las negociaciones de paz promovidas por Belisario Betancur con la guerrilla de las Fuerzas Armadas Revolucionarias de Colombia (FARC) (Cepeda, 2006).

Fue precisamente esta trágica comparación la que permitió que varios agentes del Estado, luego de reanudados los enfrentamientos entre el gobierno y las FARC, identificaran a activistas sociales y líderes comunitarios de la UP como integrantes 
de las FARC, por lo que se valieron de todas las artimañas para eliminarlos, intentando dar un golpe a las FARC, sin embargo, este no fue ningún golpe a las guerrillas sino al propio movimiento social. Por estos hechos, hubo miles de partidarios de la Unión Patriótica asesinados (p. 9); los eventos se conocieron como "el genocidio de la Unión Patriótica".

En este punto, puede verse claramente el carácter reorganizador que tuvo el genocidio de la Unión Patriótica, pues los asesinatos se dieron en el marco de una pugna entre el modelo económico que quería imponer el Gobierno, en pro de los beneficios de una élite económica y política, y contra las comunidades los sectores sociales. En este caso, el Gobierno, a través de sus agentes y en connivencia con grupos paramilitares (Sala de Reconocimiento de Verdad, 2019), asesinó a los líderes más visibles y a muchos militantes de la Unión Patriótica, a partir de lo cual pudo desarticular el movimiento, de tal manera que no logró recuperar el apoyo que alguna vez tuvo.

Este genocidio reorganizó las relaciones al interior de la sociedad, pues, mediante el miedo causado por los asesinatos, impidió que los simpatizantes del movimiento se relacionaran con los militantes, lo que redujo al grupo y eliminó los vínculos sociales que lo sostenían. Desde la desarticulación de la resistencia representada por la Unión Patriótica, se logró imponer en la Constitución de 1991 el modelo neoliberal como guía económica en el país (Cruz, 2010).

La seguridad democrática del expresidente Uribe Vélez tuvo influencia de la doctrina de la seguridad nacional, en tanto sigue estando vigente en el dogma aprendido por los integrantes de las fuerzas militares colombianas (Chaparro y Galindo, 2009), pero también coincidió con el establecimiento del Estado de seguridad, constituido como "bastión de defensa" contra la "amenaza terrorista global" (Calveiro, 2012).

La doctrina de la lucha antiterrorista no dista mucho de la relativa a la seguridad nacional, en cuanto estigmatización de un grupo político o social como "el otro negativo" y su marcación para que sea repudiado, aislado y hostigado por determinada agrupación social, para que pueda, finalmente, ser eliminado tanto física como simbólica e históricamente. Sin embargo, a diferencia de la doctrina de la seguridad nacional, la antiterrorista presenta al terrorista no como un "enemigo interno" sino como un outsider (Becker, 2009), un sujeto desquiciado que ni siquiera hace parte del grupo social y busca causar el máximo daño posible solo para desequilibrar la sociedad.

En el modelo de la seguridad democrática, el expresidente consideró que en Colombia no había un conflicto armado, sino una "amenaza terrorista"; pasó a considerar 
a todos los grupos beligerantes como armados terroristas y buscó su eliminación material. Para llevar a cabo este objetivo, montó un sistema de incentivos "por muerto" en las fuerzas militares, lo que terminó redundando en los trágicos sucesos de las ejecuciones extrajudiciales llamadas "falsos positivos". En ellas, los integrantes del ejército asesinaban a ciudadanos, los vestían como guerrilleros y los hacían pasar por muertos en combate, ejecutándolos fuera de este y en clara indefensión (Corte IDH, 2018).

La seguridad democrática, entonces, también fue un genocidio reorganizador, pero esta vez no para imponer un modelo económico y social, como el construido en la Constitución de 1991, sino para exterminar a los grupos que impedían la hegemonía total del que habían establecido previamente. Así, llevaron a cabo el asesinato selectivo de líderes comunitarios y sociales, pero también de personas del común, para generar zozobra en la población e impedir cualquier tipo de acción de resistencia. Además, en dicho modelo destaca la creación de la "red de informantes" (Beltrán, 2013) del Grupo de Acción Unificada por la Libertad Personal (GAULA), que degeneró los vínculos sociales porque creó la desconfianza entre los integrantes del mismo grupo social, dado que ahora cualquiera podría "delatar" al otro. Por ello, se desintegraron las relaciones sociales, provocando que el único enlace confiable para los integrantes del grupo fuera el construido por el Estado, destruyendo los vínculos sociales y atomizando aún más las relaciones ya existentes (Feierstein, 2008,). Esta atomización tiene un claro sentido reorganizador, porque una sociedad fragmentada no se organiza, ni presenta ningún tipo de resistencia.

Cabe anotar, que no deben entenderse los dos procesos aludidos como aislados o separados; más bien, conforman dos partes del mismo proceso genocida. En efecto, si en el genocidio de la Unión Patriótica el fin era eliminar la organización de las comunidades y colectividades en torno a un proyecto común que encaraba a los intereses de las élites políticas y económicas, en el causado por la seguridad democrática el propósito era desarticular las propias relaciones sociales para atomizar a todos los sujetos e impedir que se conectaran entre ellos. Más que dos genocidios separados, fueron la optimización de la práctica social genocida, la cual vino a perfeccionarse con el asesinato de LSyDDH que se está gestando en este momento.

El proyecto económico fue impuesto gracias a la desarticulación y reorganización obtenida con el genocidio de la Unión Patriótica, sin embargo, logró consolidarse gracias a la política de la seguridad democrática y hoy intenta aniquilar los "últimos vestigios" de resistencia — desde la perspectiva de los perpetradores-, a través de la eliminación sistemática de los líderes sociales (reductos restantes de la resistencia frente al modelo económico extractivista y latifundista que quieren imponer las élites tanto económicas como políticas colombianas). 
Pero ese proyecto genocida no vino solo con las masacres y asesinatos masivos, sino que, también de manera posterior, se vino a legitimar, con la participación de los medios de comunicación (Martin, 2015). Estos sirvieron para justificar los falsos positivos, mostrándolos como "bajas en combate legítimas", y negar el genocidio, argumentando que eran "guerrilleros dados de baja" y nunca ciudadanos ejecutados extrajudicialmente o desaparecidos (Díaz, 2011). Tal complicidad fue la que perfeccionó el genocidio, pues, una vez ocurrida la eliminación física de quienes se oponían a las políticas económicas y políticas de las élites colombianas, también fueron eliminados simbólicamente (Díaz, 2011), al negárseles su personalidad, ser reducidos a "terroristas" o "guerrilleros" y borrárseles históricamente mediante la consideración de "bajas en combate".

\section{Contexto actual del conflicto armado}

John Paul Lederach (2003) realizó una descripción del conflicto armado en Colombia que aún mantiene vigencia, pues, pese a que existen algunos actores armados quienes ya se han desmovilizado, se ejercen las mismas presiones y se realizan mecánicas de victimización iguales hoy. Así, Lederach (2003) identifica que: (i) en las regiones azotadas por el conflicto armado, existe una profunda polarización y los actores armados obligan a las personas a tomar partido: o son afines a la guerrilla o a los paramilitares y al Estado; (ii) la situación económica es crítica, por lo que se incentiva el uso de cultivos ilícitos para poder sobrevivir; (iii) existen asesinatos masivos y desplazamientos forzados en masa, por el temor a quedar en medio de las confrontaciones entre los grupos armados; (iv) hay una crisis de ingobernabilidad en las zonas más golpeadas por la violencia, ahondada por la corrupción; (v) se da una pérdida de la identidad grupal, una creciente desconfianza entre pares por el miedo a que el vecino sea un delator, privación de pertenencia, de lazos familiares y procesos de menoscabo de valores difíciles de superar, incluso con ayuda psicosocial; (vi) se genera un hostigamiento a los LSyDDH que intentan visibilizar las problemáticas regionales.

Somos Defensores (2018) identifica que la victimización se concentra en aquellas zonas en las cuales grupos empresariales y económicos tienen intereses extractivistas. A esto podríamos añadir que resulta cuanto menos curioso que se haya iniciado un megaproyecto energético en el lugar donde se realizaron las masacres de Ituango, con tierras que fueron adquiridas a precios irrisorios por parte de las personas a cargo de la hidroeléctrica Hidroituango, terrenos adquiridas de personas despojadas por las masacres realizadas por paramilitares (Torres, 2018).

En la sentencia contra Jesús Ignacio Roldán, la Sala de Justicia y Paz del Tribunal Superior del Distrito Judicial de Medellín (2014), la Sala consideró que los 
paramilitares se encontraban asociados a varios grupos tanto empresariales como de élites políticas locales y tenían la intención de romper el tejido social, contribuyendo a la consolidación de proyectos económicos en las regiones donde tuvieron influencia, con el afán de imponer un nuevo orden social, político y económico en el país. Para esto, se valieron del señalamiento a quienes se oponían a sus proyectos económicos y laborales: los llamaron "guerrilleros" o "colaboradores de la guerrilla", convirtiéndolos, instantáneamente, en objetivos militares.

\section{El asesinato de líderes sociales y defensores de derechos humanos en los territorios como "genocidio reorganizador" y la adecuación típica de estos asesinatos como genocidio contra un grupo nacional}

\section{Asesinato de líderes sociales y defensores de derechos humanos en los territorios como "genocidio reorganizador"}

Según cifras de Indepaz y Marcha Patriótica (2019), los asesinatos de LSyDDH se concentran en las zonas en las cuales existen intereses económicos de los perpetradores; esto dado que el grupo por proteger se convierte en una "piedra en el zapato" para ellos (Somos Defensores, 2018). La razón por la cual la población por proteger se convierte en una molestia para los perpetradores radica en que dicho grupo tiene un rol fundamental en su comunidad, lo que le permite resistir a las amenazas $u$ ofertas por parte de esos actores económicos, para evitar que realicen proyectos extractivistas o de índole latifundista (v. gr. de monocultivos) en sus territorios.

En virtud de ese rol activo en la defensa de los derechos de las comunidades, se crea un choque, resuelto por los perpetradores a través de la eliminación de los LSyDDH de estas comunidades.

Hasta este punto, no parece existir genocidio, sin embargo, si se analiza detenidamente el asunto, se encontrarán los puntos siguientes. (i) El grupo por proteger es una piedra angular en sus respectivas comunidades, por lo que su muerte o desaparición forzada comenzará a degenerar los lazos sociales y provocará zozobra en la población, la cual resulta acabando el proyecto de resistencia contrahegemónica que era mantenido por el defensor o líder social asesinado. (ii) El defensor o líder social, previamente a su asesinato, es estigmatizado y luego de ser asesinado se justifica su muerte, indicando que tenía líos pendientes: en los medios de comunicación, se suele afirmar que su deceso correspondió a "un ajuste de cuentas" o "líos de faldas" (Somos Defensores, 2018). (iii) Como los perpetradores suelen utilizar a integrantes de la misma comunidad para ejecutar el crimen, se gesta una desconfianza y discordia en el otro, que rompe las redes de solidaridad grupales y 
degenera el vínculo social entre los integrantes de la comunidad. No menos importante, es el hecho de que, en la mayoría de casos, (iv) estos asesinatos se hacen "con lista en mano" de los supuestos colaboradores de las guerrillas o grupos armados, que se ha obtenido a través de "denuncias anónimas" por parte de integrantes de la misma comunidad; en este punto, es evidente un quiebre de las relaciones del grupo social por causa de la delación. (v) Tras la muerte del líder o defensor, el actor económico obtiene una negociación con la comunidad para adelantar su proyecto económico, utilizando la típica frase "o vende, o nos entendemos con la viuda" (Sala de Justicia y Paz, párr. 484 d), p. 284).

A partir de lo esbozado, se puede colegir que el asesinato a LSyDDH tiene como finalidad la aniquilación del grupo social o colectividad de la cual son representantes estos líderes sociales o defensores de derechos humanos. Lo anterior, por medio de la transformación de las relaciones sociales hegemónicas al interior de la comunidad, para que pasen de ser vínculos horizontales, de confianza mutua, respeto y solidaridad, a unos en los cuales prime la desconfianza, el miedo hacia el otro y el rencor, con la finalidad de fragmentar el grupo y eliminar cualquier vestigio de resistencia u oposición al proyecto económico que quieren emprender los perpetradores en la región. En este caso, el asesinato de los LSyDDH no es "en sí" el objetivo, sino que se persigue desarticular la comunidad, a través del miedo y la desconfianza, con el propósito de impedir que se generen procesos de resistencia al modelo económico que se desea imponer; en otras palabras, la destrucción de la identidad de la comunidad, para imponer la de los perpetradores (Feierstein, 2016).

En efecto, los asesinatos a LSyDDH tienen como objetivo, como bien lo reconoció la Sala de Justicia y Paz del Tribunal Superior del Distrito Judicial de Medellín (2014), imponer un nuevo orden social, político y económico en el país, sin oposiciones, para terminar la implementación del modelo económico tanto extractivista como latifundista y con ello construir un pacto social novedoso, basado en la existencia y agudización de las clases sociales. En este, las élites seguirán acumulando riqueza y poder a costa del empobrecimiento del resto de la población, al igual que del deterioro constante del ambiente y el territorio.

\section{Genocidio de líderes sociales como genocidio contra un grupo nacional}

Indicó el relator especial sobre el proyecto de código de crímenes contra la paz y la seguridad de la humanidad, Doudou Thiam, el 11 de marzo de 1986, en su cuarto informe, que: "[e]l concepto de nación no coincide con el grupo étnico y se caracteriza por la voluntad de vivir en común, un ideal común, un objetivo común e inspiraciones comunes" (párr. 57). Esto implica, que las características definitorias 
de un grupo nacional responden a aquel que tiene en común un ideal, un objetivo e inspiraciones. Asimismo, indicaba el relator que: "prácticamente la totalidad de los Estados (...) tienen una población heterogénea", por lo que también se puede entender que en un mismo Estado puedan existir diversos subgrupos nacionales (Giraldo, 2004).

Precisamente lo dicho en este apartado permite asumir que los LSyDDH forman parte de un grupo nacional, por cuanto tienen objetivos, ideales y proyectos comunes, traducidos en la oposición al modelo económico neoliberal, extractivista y latifundista que los perpetradores quieren imponer en cada uno de sus territorios (Langheinrich, 2017). Además, el asesinato de un líder social o un defensor de derechos humanos, al darse contra un cabecilla de una comunidad, resulta "aniquilando" política y organizativamente a toda la comunidad, así como a todos sus procesos de resistencia contra el modelo económico que quieren imponer los perpetradores (Torres, 2018, pp. 387 y ss.). Es decir, al encarnar los LSyDDH los "últimos vestigios de resistencia" en los territorios, ante el modelo extractivista y latifundista que se está terminando de consolidar, se les está exterminando con miras a destruir dicha resistencia y consolidar el proceso de reorganización social.

En virtud de lo ya expuesto, puede deducirse que el asesinato a LSyDDH es un genocidio en contra de un grupo nacional, protegido por la Convención contra el genocidio; dicho genocidio tiene como objetivo reorganizar las relaciones sociales al interior de los territorios donde se realiza, para erradicar toda oposición al prototipo extractivista y latifundista que se desea imponer.

\section{Conclusiones}

De lo expuesto se puede concluir:

1. El grupo por proteger "líderes sociales y defensores de derechos humanos" es homogéneo, en términos políticos y prácticos, y puede catalogarse como "grupo nacional", en cuanto que comparte ideales, objetivos y proyectos comunes, los cuales se traducen en la defensa de territorios y comunidades de las injerencias de actores económicos y armados - "perpetradores"Estos últimos tienen la intención de imponer un modelo económico basado en el extractivismo y el mantenimiento de los latifundios.

2. El genocidio es una categoría viva que debería construirse atendiendo a las dinámicas sociales y a la evolución misma de la sociedad; en este sentido, es evidente que, hoy, los genocidios se realizan principalmente por motivos políticos, como sentenciaba el representante francés en la discusión sobre la introducción o no de los grupos políticos en la Resolución 96 de 1946. 
Es por ello que se debe ampliar el criterio, para brindar protección a los grupos políticos, sin embargo, mientras ello no pase, se podrán conceptualizar, tal como lo han hecho algunos autores como Baltasar Garzón, Carlos Rozanzki y Daniel Feierstein, como genocidios en grupos nacionales protegidos.

3. El genocidio realizado en Colombia es un proyecto reorganizador que tuvo tres momentos. Comenzó con la imposición del modelo económico, para lo que se valió del genocidio de la Unión Patriótica. Continuó con la eliminación de la posibilidad de reorganización social, a través de la atomización social gestada por la seguridad democrática, tratando a los opositores al modelo económico como "terroristas", perpetuando el genocidio simbólico. Por último, se vale del asesinato de los líderes sociales para expandir el ya nombrado proyecto reorganizador, en aquellos lugares que aún están resistiendo al modelo financiero hegemónico que se anhela imponer.

4. Es necesario propugnar una resistencia civil ante la notoria escalada de violencia sociopolítica que se vive con ocasión del modelo neoliberal impuesto, de índole extractivista, latifundista y colonialista, pues es a través de ese comportamiento que lograremos atajar las embestidas contra los LSyDDH, quienes son la última línea en la defensa del territorio, los derechos de las comunidades y los más pobres. Para llevar a cabo esta tarea, debemos continuar visibilizando las agresiones, con el propósito de evitar que caigan en el olvido y la impunidad, porque es la única manera de evitar que se consolide el genocidio tanto simbólica como históricamente. Con el mantenimiento de la memoria y la consciencia de que los hechos son para imponer un modelo económico, impediremos que los perpetradores finalicen de manera exitosa su programa de reorganización social, política y monetaria.

\section{Referencias}

Ambos, K. (2004). Problemas seleccionados en torno a los crímenes más graves (core crimes) en el Derecho Penal Internacional. (9 de febrero de 2020). Ministerio Público Fiscal de Argentina. https://www.mpf.gov.ar/docs/RepositorioB/Ebooks/qdpi080.pdf

Becker, H. (2009). Outsiders: hacia una sociología de la desviación. Buenos Aires: Siglo veintiuno editores.

Beltrán, M. (2013). Colombia: de la "Seguridad Democrática" a la "Política integral de Seguridad y Defensa para la Prosperidad. Revista Conflicto Social, año 6, (9), pp. 12-38. 
Bjornlund, M.; Markusen, E. y Mennecke, M. (2005). ¿Qué es el genocidio? En la búsqueda de un denominador común entre definiciones jurídicas y no jurídicas. En D. Feierstein (Ed.), Genocidio. la administración de la muerte en la modernidad (pp. 17-49). Buenos Aires: Eduntref.

Calveiro, P. (2012). Violencias de Estado: la guerra antiterrorista y la guerra contra el crimen como medios de control global. Buenos Aires: Siglo veintiuno editores.

Castañeda-Durán, J. (2019). Las agresiones a los líderes sociales y defensores de derechos humanos como crímenes de lesa humanidad justiciables por la Corte Penal Internacional. Artículo entregado para publicación.

Cepeda, I. (2006). Genocidio político: el caso de la Unión Patriótica en Colombia. Revista CEJIL, Debates sobre Derechos Humanos y el Sistema Interamericano, Año 1 (2), pp. $101-112$.

Chaparro, A. y Galindo, C. (2009). Génesis y Transformaciones del Estado Nación en Colombia: una mirada topológica a los estudios sociales desde la filosofía política. Escuela de Ciencias Humanas. Bogotá: Editorial Universidad del Rosario. 346 p.

Churchill, W. (1997). A little Matter of Genocide: Holocaust and Denial in the Americas, 1492 to the Present. San Francisco: City Lights Books.

Comisión de Derechos Humanos del Consejo Económico y Social de Naciones Unidas. Subcomisión de Prevención de la Discriminación y Protección de las Minorías. (1985). Informe revisado y actualizado sobre la cuestión de la prevención y sanción del crimen de genocidio preparado por el señor Benjamín Whitaker. E/CN.4/Sub.2/1985/6, 2 de julio de 1985.

Comisión Interamericana de Derechos Humanos. (1997). Informe No. 5/97. Caso 11.227 "Genocidio de la Unión Patriótica". Informe de admisibilidad, 12 de marzo de 1997.

Comisión Interamericana de Derechos Humanos. (2011). Segundo informe sobre la situación de las defensoras y defensores de los derechos humanos en las Américas. Documento de la Organización de Estados Americanos OEA/Ser. L/V/II. Doc. 66, rev. 1,31 de diciembre.

Corte Interamericana de Derechos Humanos. (2018). Caso Villamizar Durán y otros vs. Colombia. Sentencia de Excepción Preliminar, Fondo, Reparaciones y Costas del 20 de noviembre de 2018.

Cruz, L. (2010). La constitución política de 1991 y la apertura económica. Revista Facultad de Ciencias Económicas, XVIII (1), 269-280. 
Díaz, L. (2011). Desaparición forzada en Colombia: medios de comunicación y memoria. Maestría en Derechos Humanos y Democracia. México: FLACSO.

Feierstein, D. (2008). El genocidio como práctica social: entre el nazismo y la experiencia argentina. Primera reimpresión. Buenos Aires: Fondo de Cultura Económica.

Feierstein, D. (2016). El concepto de genocidio y la "destrucción parcial de los grupos nacionales". Algunas reflexiones sobre las consecuencias del derecho penal en la política internacional y en los procesos de memoria. Revista Mexicana de Ciencias Políticas y Sociales, año LXI, (228), 247-266.

Giraldo, J. (2004). La práctica del Genocidio en Colombia. Recuperado de http://www. javiergiraldo.org/spip.php?article91

Guevara, C. (2019). Panorama de las personas defensoras de derechos humanos y líderes sociales en riesgo en Colombia, 2018-2019. Policy Brief, 1-2019. Bogotá: Instituto Colombo-Alemán para la Paz - CAPAZ.

Indepaz y Marcha Patriótica. (2019). Separata de actualización 23 de mayo de 2019. En Todos los nombres, todos los rostros: Informe de derechos humanos sobre la situación de líderes/as y defensores de derechos humanos en los territorios. Bogotá: Indepaz, Cumbre Agraria y Marcha Patriótica.

Jurisdicción Especial para la Paz. Sala de Reconocimiento de Verdad, de Responsabilidad y de Determinación de los Hechos y Conductas. (2019). Auto No. 27 de 26 de febrero de 2019 "mediante el cual avoca conocimiento del Caso No. 006 sobre la Victimización de miembros de la Unión Patriótica (UP) por parte de agentes del Estado. Bogotá: JEP.

Juzgado Central de Instrucción No. 5. (1998). Auto del Juzgado Central de Instrucción $N^{o} 5$ (España), de 10 de diciembre de 1998, por el que se procesa a Augusto Pinochet por delitos de genocidio, terrorismo y torturas. Madrid: Audiencia Nacional.

Langheinrich, P. (2017). Defender el territorio y el ambiente en contextos de actividad de empresas extractivas. Bogotá: Cajar, FIDH y OMCT.

Lederach, J. (2003). Tejiendo relaciones, estrategias de diálogo y negociación en contextos de conflicto armado. Bogotá: Justapaz.

Lemkin, R. (2008). El dominio del Eje en la Europa ocupada. Buenos Aires: Prometeo Libros.

Martín, M. (2015). Criminalización de Defensoras y Defensores de Derechos Humanos. Categorización del fenómeno y medidas para su afrontamiento. Bruselas: Protection International. 
Somos Defensores. Sistema de Información sobre Agresiones a Defensores (as) de Derechos Humanos. (2018). Piedra en el Zapato. Informe anual 2017. Bogotá: Programa Somos Defensores.

Thiam, D. (1984). Cuarto informe sobre el proyecto de código de crímenes contra la paz y la seguridad de la humanidad, por el Sr. Doudou Thiam, Relator Especial. Documento A/CN.4/398.

Torres, A. (2018). Colombia Nunca Más. Extractivismo - Graves violaciones a Derechos Humanos. Caso Hidroituango. Una lucha por la memoria y contra la impunidad. Medellín: Corporación Jurídica Libertad.

Tribunal Oral en lo Federal No. 1 de la Plata. (2006). Fallo condenatorio a Miguel Etchecolatz. Causa N. 2251/06.

Tribunal Superior del Distrito Judicial de Medellín, Sala de Justicia y Paz. (2014). Sentencia del 1 de septiembre de 2014. Rad. 11001-22-52000-2014-00019-00 Rad. Interno 2319. M. P. Dr. Eduardo Castellanos Roso.

Tribunal Superior Distrito Judicial de Medellín, Sala de Justicia y Paz. (2015). Sentencia del 2 de febrero de 2015. Rad. 110016000253200680018. M. P. Dra. María Consuelo Rincón Jaramillo.

Tribunal Penal Internacional para Ruanda. (1999). Prosecutor vs. Georges Anderson Nderbubumwe Rutaganda. Case No. ICTR-96-3-T. Judgement and Sentence, 6 de diciembre de 1999. 
